\title{
TINJAUAN PERENCANAAN STRUKTUR GEDUNG KANTOR DINAS PERDAGANGAN KOTA SORONG
}

\author{
A. Didik Setyo Purwantoro ${ }^{1)}$, Ertson Steven Mangandar Saragih ${ }^{2)}$ \\ 1) 2) Program Studi Teknik Sipil Universitas Muhammadiyah Sorong \\ Jalan Pendidikan No 27 Kota Sorong, Propinsi Papua Barat \\ Email : didikumsorong@gmail.com
}

\begin{abstract}
ABSTRAK
Perencanaan struktur gedung tahan gempa harus di rencanakan menggunakan metodeSistem Rangka Pemikul Momen, dimana Sistem Rangka Pemikul Momen adalah Sistem rangka ruang dalam dimana komponen-komponen struktur dan join-joinnya menahan gaya-gaya yang bekerja melalui aksi lentur, geser dan aksial. Dengan adanya system ini diharapkan suatu bangunan dapat berperilaku daktail yang nantinya akan mentransfer gaya gempa serta membatasi beban gempa yang bekerja pada struktur. Pada penelitian ini penulis ingin meninjau struktur gedung 3 lantai Kantor Dinas Perdagangan Kota Sorong dengan menggunakan metode Sistem Rangka Pemikul Momen Menengah dan Sistem Rangka Pemikul Momen Khusus yang dihitung berdasarkan SNI 03-2847-2002 dan SNI 1726-2012. Dari hasil perhitungan struktur bangunan metode SRPMK Beban Gempa yang bekerja pada arah x sebesar $46.993 \mathrm{Kg}$ dan arah y sebesar $70.490 \mathrm{Kg}$, sedangkan untuk SRPMM Beban Gempa yang bekerja pada arah-x sebesar $75.189 \mathrm{Kg}$ dan arah-y sebesar $112.783 \mathrm{Kg}$, sehingga Beban gempa yang bekerja pada struktur bangunan metode SRPMK lebih kecil dibandingkan dengan struktur bangunan metode SRPMM, yakni sebesar 1,6\%.
\end{abstract}

Katakunci : SRPMK, SRPMM, Strong Column Weak Beam, SNI 03-2847-2002, SNI 1726-2002. 


\section{PENDAHULAN \\ Latar Belakang}

Secara umum Kantor merupakan sebuah badan organisasi yang terdiri dari tempat, personil dan operasi ketatausahaan untuk membantu pimpinan organisasi. Kantor mempunyai beberapa fungsi di antaranya, yaitu menerima informasi, merekam informasi, mengatur informasi, memberi informasi dan melindungi aset atau harta.

Kantor Dinas Perdagangan Kota Sorong dengan 3 lantai yang berlokasi di Jalan Pramuka, Remu Utara, Kota Sorong. Dimana Kota Sorong ini merupakan daerah rawan Gempa.

Perencanaan pembangunan struktur gedung tahan gempa harus di rencanakan menggunakan metode Sistem Rangka Pemikul Momen, dimana Sistem rangka pemikul momen dikelompokkan menjadi : Sistem Rangka Pemikul Momen Biasa, Sistem Rangka Pemikul Momen Menengah dan Sistem Rangka Pemikul Momen Khusus.

Oleh karena itu pada penelitian ini penulis ingin meninjau struktur gedung 3 lantai Kantor Dinas Perdagangan Kota Sorong dengan menggunakan metode Sistem Rangka Pemikul Momen Menengah dan Sistem Rangka Pemikul Momen Khusus yang dihitung berdasarkan Tata Cara Perencanaan Perhitungan Struktur Beton untuk Bangunan Gedung (SNI 03-2847-2002) dan Tata Cara Perencanaan Ketahanan Gempa untuk Struktur Bangunan Gedung dan Non Gedung (SNI 1726-2012).

\section{Batasan Masalah}

Untuk mendapatkan hasil penelitian yang optimal dan kemudahan dalam perencanaan struktur ini, maka penulis memberikan batasanbatasan sebagai berikut :

a. Pedoman perhitungan menggunakan SNI Gempa 1726-2012, SNI Beton 03 - 2847 2002) dan PPPURG 1987.

b. Tinjauan perencanaan struktur atas meliputi : balok, kolom dan pelat lantai sedangkan struktur bawah hanya pondasi telapak.

c. Perhitungan struktur menggunakan metode SRPMK dan SRPMM pada wilayah gempa menengah.

d. Analisis gaya-gaya dalam menggunakan program SAP 2000.

\section{Tujuan Penelitian}

Adapun tujuan yang diharapkan dari tinjauan perencanaan struktur gedung ini adalah sebagai berikut :

a. Mengetahui berapa besar dimensi struktur atas, yakni balok, kolom dan pelat lantai.

b. Mengetahui berapa besar perbandingan hasil perhitungan struktur dan beban gempa yang bekerja pada struktur gedung dengan metode sistem rangka pemikul momen menengah dan sistem rangka pemikul momen khusus.

c. Mengetahui berapa besar dimensi struktur bawah, yakni pondasi telapak.

\section{METODOLOGI PENELITIAN Lokasi dan Waktu Penelitian}

Lokasi proyek pembangunan gedung kantor dinas perdagangan kota sorong ini terletak di Jalan Pramuka, Remu Utara, tepatnya berada disebelah barat kantor walikota sorong. Untuk lebih jelasnya, dapat di lihat pada foto satelit di bawah ini :

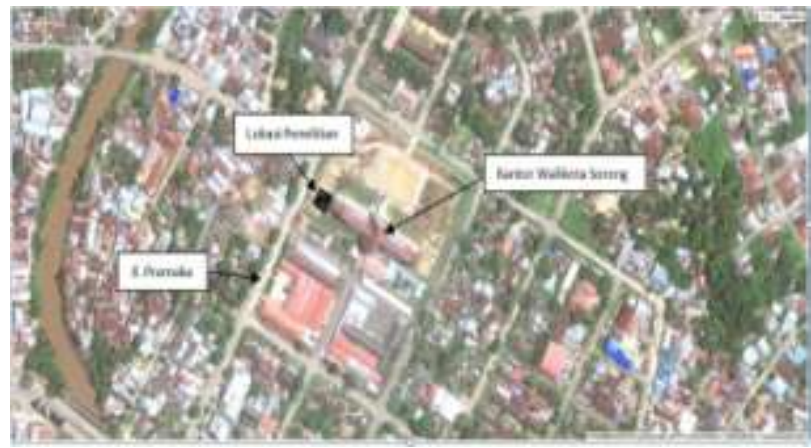

Gambar 3. Peta Lokasi Penelitian

Semua metode penulisan dan analisa dalam artikel ilmiah ini merujuk pada panduan penulisan tugas akhir Fakultas Teknik Universitas Muhammadiyah Sorong tahun 2014 (Pristianto, Amri, \& Rusdi, 2014).

\section{Data Geometrik Struktur}

\section{Dimensi Gedung}
a. Type Bangunan
: Perkantoran
b. Panjang Bangunan : $21,6 \mathrm{~m}$
c. Lebar Bangunan : $14,4 \mathrm{~m}$
d. Tinggi Bangunan : $11,45 \mathrm{~m}$
e. Jumlah Lantai : 3 Lantai

\section{Fungsi Gedung}
a. Lantai I
: Ruang Perkantoran
b. Lantai II : Ruang Perkantoran
c. Lantai III : Ruang Utilitas 


\section{Data Material}

\section{Beton}

Material beton yang digunakan pada struktur ini adalah material beton dengan kuat tekan (f'c) sebesar $25 \mathrm{MPa}$.

\section{Baja Tulangan}

Kuat tarik leleh (fy) baja tulangan yang digunakan untuk struktur direncanakan sebesar $400 \mathrm{MPa}$ untuk tulangan utama, dan $240 \mathrm{MPa}$ untuk tulangan sengkang.

\section{Tahapan penelitian}

Berikut adalah Diagram Alir untuk Tahapantahapan dalam penelitian penelitian ini :

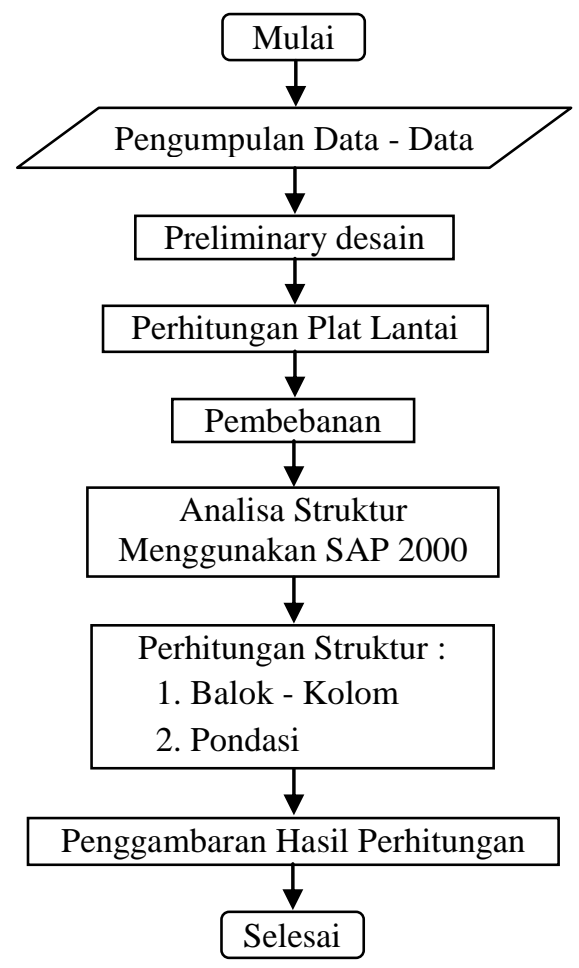

Gambar 4. Diagram Alir Tahapan Penelitian

\section{PERHITUNGAN STRUKTUR Perencanaan Dimensi}

Tabel 1. Perencanan Dimensi Balok

\begin{tabular}{cccccc}
\hline Lantai & \multicolumn{4}{c}{ Balok Induk } \\
\cline { 2 - 6 } & $\mathrm{L}(\mathrm{cm})$ & \multicolumn{2}{c}{$\mathrm{h}(\mathrm{cm})$} & $\mathrm{b}(\mathrm{cm})$ \\
\hline I & 720 & $1 / 14 . \mathrm{L}$ & 55 & $2 / 3 . \mathrm{h}$ & 35 \\
\hline II & 720 & $1 / 14 . \mathrm{L}$ & 55 & $2 / 3 . \mathrm{h}$ & 35 \\
\hline III & 720 & $1 / 14 . \mathrm{L}$ & 55 & $2 / 3 . \mathrm{h}$ & 35 \\
\hline Atap & 720 & $1 / 16 . \mathrm{L}$ & 45 & $2 / 3 . \mathrm{h}$ & 30 \\
\hline
\end{tabular}

Tabel 2. Perencanaan Kolom

\begin{tabular}{cccc}
\hline Lantai & \multicolumn{3}{c}{ Kolom } \\
\cline { 2 - 4 } & $\mathrm{H}(\mathrm{cm})$ & $\mathrm{h}(\mathrm{cm})$ & $\mathrm{b}(\mathrm{cm})$ \\
\hline I & 380 & 50 & 50 \\
\hline II & 380 & 50 & 50 \\
\hline III & 385 & 45 & 45 \\
\hline
\end{tabular}

\section{Perencanaan Plat Lantai}

Plat Lantai ukuran $7.200 \mathrm{~mm}$ x $7.200 \mathrm{~mm}$

Diperoleh tulangan Plat Lantai sebagai berikut :

Momen lapangan arah $\mathrm{x}$ :

$\mathrm{A}_{\mathrm{slx}}=592 \mathrm{~mm}^{2}$; dipilih D10-100 $=785 \mathrm{~mm}^{2}$ Momen lapangan arah y :

$\mathrm{A}_{\text {sly }}=644 \mathrm{~mm}^{2}$; dipilih D10-100 $=785 \mathrm{~mm}^{2}$ Momen Tumpuan arah x :

$\mathrm{A}_{\mathrm{stx}}=1.251 \mathrm{~mm}^{2}$; dipilih D14-100 =1.539 $\mathrm{mm}^{2}$ Momen Tumpuan arah y :

$\mathrm{A}_{\text {siy }}=1.366 \mathrm{~mm}^{2}$; dipilih D14-100 $=1.539 \mathrm{~mm}^{2}$

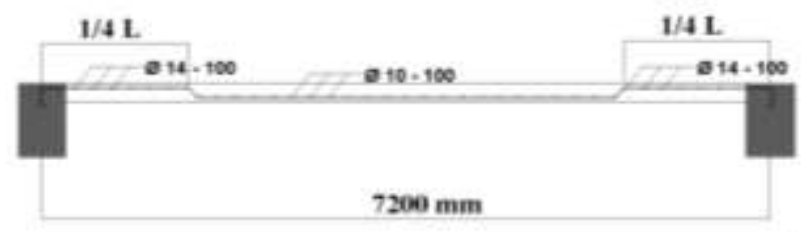

Gambar 5. Tulangan Plat lantai 1 arah x

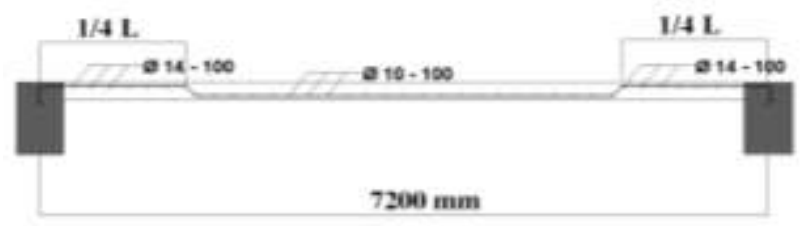

Gambar 6. Tulangan Plat lantai 1 arah y

\section{Menghitung Berat Total Gedung (Wt)}

Total berat gedung merupakan jumlah beban dari tiap lantai. Jadi, total keseluruhan berat gedung adalah :

W atap $=807.506 \mathrm{Kg}$

W lantai 3

$=406.760 \mathrm{Kg}$

W lantai 2

$=433.292 \mathrm{Kg}$

W lantai 1/lantai dasar

$$
=\underline{428.207 \mathrm{Kg}+}
$$

\section{Menghitung Gaya Geser Dasar (V)}

$$
\mathrm{Wt}=2.075 .765 \mathrm{Kg}
$$

Gaya geser dasar (V) untuk SRPMK :

$$
\begin{aligned}
\mathrm{V} & =\mathrm{Cs} . \mathrm{Wt} \\
& =0,122 \times 2.075 .765 \mathrm{Kg} \\
& =253.762 \mathrm{Kg}
\end{aligned}
$$

Gaya geser dasar (V) untuk SRPMM :

$$
\begin{aligned}
\mathrm{V} & =\mathrm{Cs} . \mathrm{Wt} \\
& =0,196 \times 2.075 .765 \mathrm{Kg} \\
& =406.020 \mathrm{Kg}
\end{aligned}
$$

\section{Perhitungan Sistem Rangka Pemikul Momen Khusus}

1. Perhitungan Tulangan Lentur dan Geser Balok Lantai 1

a. Tinjauan pada Balok D 400x550 mm

b. Menentukan tinggi efektif balok : $\mathrm{d}=550-40-10-1 / 219=491 \mathrm{~mm}$

c. Cek apakah balok memenuhi syarat SNI 03-2847-2002 Pasal 23.3.1 : 
- $\quad \mathrm{Pu}=7,96 \mathrm{KN}<0,1$. Ag. f'c $=440$

KN... Syarat terpenuhi

- $\mathrm{Ln}=6.700 \mathrm{~mm}>4 \mathrm{xd}=1.962$ $\mathrm{mm}$... Syarat terpenuhi

- Rasio b/h $=0,7>0,3 \ldots$ Syarat terpenuhi.

d. Momen Maksimal pada Balok

\begin{tabular}{clc}
\hline Kondisi & \multicolumn{1}{c}{ Lokasi } & $\mathrm{Mu}(\mathrm{KN})$ \\
\hline 1 & Momen Tumpuan Negatif & $-287,9104$ \\
\hline 2 & Momen Tumpuan Positif & 182,0320 \\
\hline 3 & Momen Lapangan & 158,1434 \\
\hline
\end{tabular}

e. Menghitung Keperluan Tulangan

1) Kondisi 1, Momen Tumpuan Negatif

Luas tulangan $\left(\mathrm{A}_{\mathrm{s}}\right)$ :

$\mathrm{A}_{\mathrm{s}}=\frac{287,9104}{0,85 \times 400 \times 0,85 \times 461}=2.161 \mathrm{~mm}^{2}$

Tabel 3 Penentuan Jumlah Tulangan Momen Tumpuan Negatif Balok Lantai 1 SRPMK

\begin{tabular}{|c|c|c|c|c|}
\hline \multicolumn{2}{|c|}{ Dimensi $(\mathrm{mm})$} & \multirow{2}{*}{ Jumlah } & \multirow{2}{*}{$\begin{array}{c}\mathrm{A}_{\mathrm{s}} \\
\left(\mathrm{mm}^{2}\right)\end{array}$} & \multirow{2}{*}{$\begin{array}{r}A_{\text {s pakai }} \\
\left(\mathrm{mm}^{2}\right)\end{array}$} \\
\hline Diameter & Luas & & & \\
\hline 19 & 284 & 5 & 1.420 & \multirow{2}{*}{2.560} \\
\hline 22 & 380 & 3 & 1.140 & \\
\hline
\end{tabular}

Tinggi balok tegangan tekan ekivalen yang aktual adalah:

$\alpha=\frac{2.560 \times 400}{0,85 \times 20 \times 400}=151 \mathrm{~mm}$

Cek momen nominal aktual :

$\phi \mathrm{M}_{\mathrm{n}}=\emptyset$ As.fy. $\left(\mathrm{d}-\frac{\mathrm{a}}{2}\right)$

$\phi \mathrm{M}_{\mathrm{n}}=315,9703 \mathrm{KNm}>\mathrm{M}_{\mathrm{u}}=$ 287,9104 KNm....OK

Cek As minimum :

$A_{s \text { min }}=\frac{\sqrt{f^{\prime} c}}{4 \cdot f y} \cdot b \cdot d=515 \mathrm{~mm}^{2}$

Tetapi tidak boleh kurang dari :

$\frac{1,4}{\text { fy }} \cdot$ b.d $=645 \mathrm{~mm} 2 \ldots$ Ok, syarat

As minimum terpenuhi

Cek rasio tulangan :

$\rho=\frac{\text { As }}{\text { b.d }}=\frac{2.560}{400 \times 461}=0,0139$

Rasio tulangan $\rho$ berdasarkan

SNI 03-2847-2002 pasal 23.3.2

adalah $\rho<0,025$

$\rho=0,0139<0,025 \ldots$ OK

Cek apakah penampang

Tension-Controlled?

$$
\frac{151}{491}<0,375 \times 0,85
$$$$
0,307<0,319 \ldots \text { OK }
$$

Jadi, digunakan tulangan 5D19 dan 3D22

2) Kondisi 2, Momen Tumpuan Positif

Digunakan tulangan 5D19

3) Kondisi 3, Momen Lapangan

Digunakan tulangan 4D19 untuk Momen tumpuan positif.
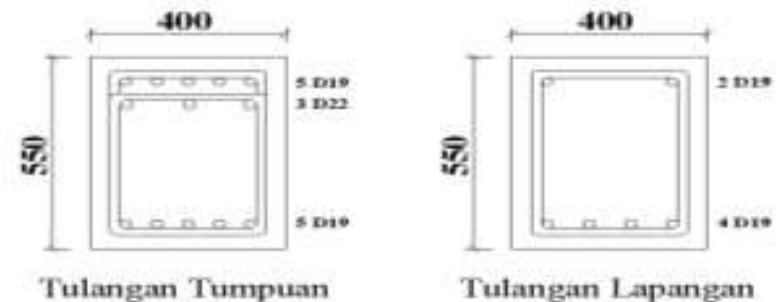

Gambar 7. Penulangan Penampang Balok Lantai 1 SRPMK

\section{Perhitungan Tulangan Longitudinal Kolom Lantai 1}

1. Tinjauan pada Kolom 500x500 mm

a) Persyaratan kolom berdasarkan SNI 03-2847-2002 pasal 23.4.1 :

- $\mathrm{P}_{\mathrm{u}}=986,144 \mathrm{KN}>$ Ag.f'c/10 = $500 \mathrm{KN} \ldots . . \mathrm{OK}$

- $\quad b=500 \mathrm{~mm}>300 \mathrm{~mm} \ldots . . \mathrm{OK}$

- Rasio b/h $=500 / 500=1>$ $0,4 \ldots . . \mathrm{OK}$

b) Desain Tulangan Longitudinal Kolom As perlu $=3.200 \mathrm{~mm}^{2}$ (Hasil Output PCACOL)

Tabel 4. Penentuan Jumlah Tulangan Longitudinal Kolom Lantai 1 SRPMK

\begin{tabular}{|c|c|c|c|}
\hline \multicolumn{2}{|c|}{ Dimensi } & \multirow{2}{*}{ Jumlah } & \multirow{2}{*}{$\begin{array}{c}\text { As } \\
\left(\mathrm{mm}^{2}\right)\end{array}$} \\
\hline Diameter & Luas & & \\
\hline 19 & 284 & 12 & 3.408 \\
\hline
\end{tabular}

Untuk menghindari panjang penyaluran yang terlalu panjang, dan $\rho_{\mathrm{g}}$ dibatasi tidak kurang dari 0,01 dan tidak lebih dari 0,06.

$\rho_{\mathrm{g}}=\frac{A_{s}}{A_{g}}=\frac{3.408}{250.000}=0.014$

Persyaratan : $0,01<\rho_{\mathrm{g}}<0,06$

$0,01<0,014<0,06 \ldots$. OK persyaratan terpenuhi.

c) Kuat Kolom

$\Sigma \mathrm{Mc}=688 \mathrm{KNm}>1,2 \Sigma \mathrm{Mg}=624$

$\mathrm{KNm} . . . \mathrm{OK}$, syarat terpenuhi 
d) Desain tulangan Confinement

Tabel 5. Penentuan Jumlah Tulangan Confinement Kolom Lantai 1 SRPMK

\begin{tabular}{cccc}
\hline \multicolumn{2}{c}{ Dimensi } & Jumlah & $\begin{array}{c}\text { As } \\
\left(\mathrm{mm}^{2}\right)\end{array}$ \\
\cline { 1 - 3 } Diameter & Luas & & 339 \\
\hline 12 & 113 & 3 & 3 \\
\hline
\end{tabular}

e) Desain tulangan Geser

$A_{v_{-} \min }=\frac{1}{3} \times \frac{\text { b.s }}{\text { fy }}=\frac{1}{3} \times \frac{500 \times 100}{240}=69 \mathrm{~mm}^{2}$ sebelumnya nilai $A_{\mathrm{sh}}$ untuk tulangan confinement 3 kaki D12 $=339 \mathrm{~mm}^{2}$ > $\mathrm{A}_{\mathrm{v}_{-} \min }=69 \mathrm{~mm}^{2}$.

Jadi, persyaratan kuat geser terpenuhi.

f) Spasi antar tulangan geser

SNI 03-2847-2002 pasal 23.4.4.6, yaitu : $6 \mathrm{x}$ diameter tulangan longitudinal $=6 \times 19=114 \mathrm{~mm}$. Jadi, dipakai spasi tulangan $=150 \mathrm{~mm}$

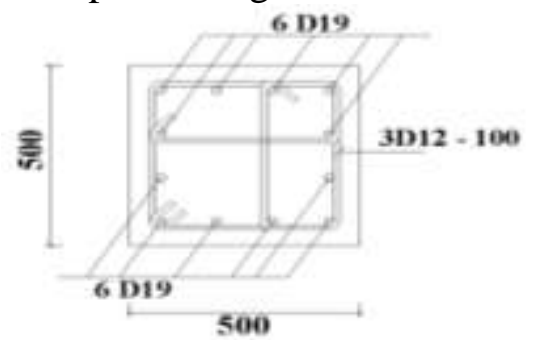

Gambar 8. Penulangan Kolom Lantai 1 dan Sengkang 3 kaki SRPMK

\section{Perhitungan Sistem Rangka Pemikul Momen Menengah}

1. Perhitungan Tulangan Lentur dan Geser Balok Lantai 1
a. Tinjauan pada
Balok
Dimensi 400x550 mm
b. Momen Maksimal pada Balok

\begin{tabular}{clc}
\hline Kondisi & \multicolumn{1}{c}{ Lokasi } & $\mathrm{Mu}(\mathrm{KN})$ \\
\hline 1 & Momen Tumpuan Negatif & $-287,7991$ \\
\hline 2 & Momen Tumpuan Positif & 182,0078 \\
\hline 3 & Momen Lapangan & 158,1434 \\
\hline
\end{tabular}

c. Menghitung Keperluan Tulangan

- Kondisi 1, Momen Tumpuan Negatif. Digunakan tulangan 6D19 dan 2D22.

- Kondisi 2, Momen Tumpuan Positif. Digunakan tulangan 5D19

- Kondisi 3, Momen Lapangan. Digunakan tulangan 4D19.

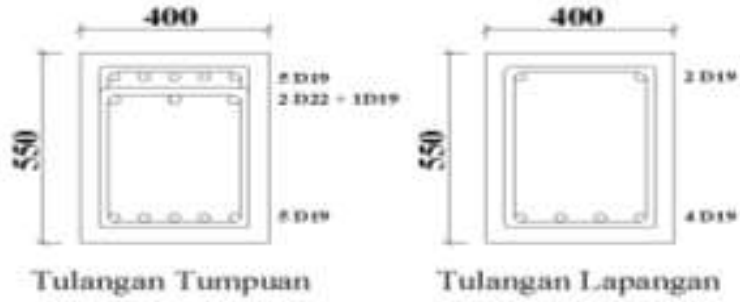

Gambar 9. Penulangan Penampang Balok Lantai

\section{Perhitungan Penulangan Longitudinal}

\section{Kolom Lantai 1}

1. Tinjauan pada Kolom 500x500 mm

a. Persyaratan kolom berdasarkan SNI 03-2847-2002 pasal 23.4.1 :

- $\quad \mathrm{P}_{\mathrm{u}}=607,914 \mathrm{KN}>$ Ag.f'c $/ 10=500$ KN...OK, syarat terpenuhi

b. Desain Tulangan Longitudinal Kolom As perlu $=3.200 \mathrm{~mm}^{2}$ (Hasil Output PCACOL)

Tabel 5 Penentuan Jumlah Tulangan Longitudinal Kolom Lantai 1 SRPMM

\begin{tabular}{cccc}
\hline \multicolumn{2}{c}{ Dimensi } & \multirow{2}{*}{ Jumlah } & $\begin{array}{c}\text { As } \\
\left(\mathrm{mm}^{2}\right)\end{array}$ \\
\cline { 1 - 3 } Diameter & Luas & & 3.408 \\
\hline 19 & 284 & 12 & 3.40 \\
\hline
\end{tabular}

$\rho_{\mathrm{g}}=\frac{A_{s}}{A_{g}}=\frac{3.408}{250.000}=0.014$

Persyaratan : $0,01<\rho_{\mathrm{g}}<0,06$

$0,01<0,014<0,06 \ldots$. OK persyaratan terpenuhi.

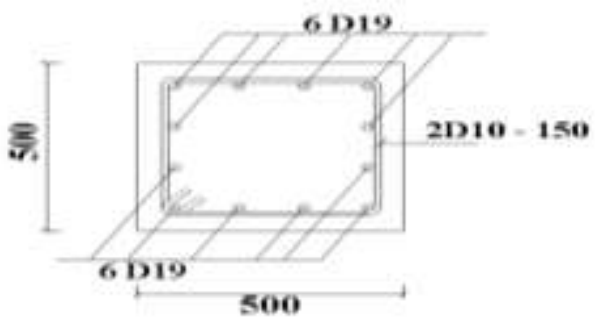

Gambar 10. Penulangan Kolom Lantai 1 SRPMM

\section{Perhitungan Pondasi Telapak}

\section{Data-data}

Berat tanah, $\gamma \mathrm{t}=18,4 \mathrm{KN} / \mathrm{m}^{3}$

Hambatan Konus, $\mathrm{qc}=13 \mathrm{~kg} / \mathrm{cm}^{2}$

Tebal tanah diatas pondasi, ha $=2,1 \mathrm{~m}$

Daya dukung tanah $\left(q_{a}\right)=942 \mathrm{KN} / \mathrm{m}^{2}$

Dimensi Pondasi, $\mathrm{B}=1,6 \mathrm{~m}$, dan $\mathrm{L}=1,6 \mathrm{~m}$

Tebal pondasi, $\mathrm{ht}=0,40 \mathrm{~m}$

Gaya aksial ultimit, $\mathrm{P}_{\text {ult }}=1.730 \mathrm{KN}$

Momen ultimit, $\mathrm{M}_{\mathrm{ult}}=98,67 \mathrm{KN}$

2. Kontrol Tegangan Tanah

a. Tekanan akibat berat pondasi telapak :

$$
q=(h t x \gamma c)+(h a x \gamma t)=48,24 \mathrm{kN} / \mathrm{m}^{2}
$$


b. Tegangan ijin tanah maksimum :

$$
\begin{aligned}
& \sigma_{\text {maks }}=\frac{P_{u l t}}{B \times L}+\frac{M_{u l t}}{\frac{1}{6} \times B \times L}+q \leq q_{a} \\
& =868 \leq 942 \ldots . . \text { Syarat terpenuhi }
\end{aligned}
$$

c. Tegangan ijin tanah minimum

$$
\begin{aligned}
& \sigma_{\text {min }}=\frac{P_{u l t}}{B \times L}-\frac{M_{u l t}}{\frac{1}{6} \times B \times L}+q \leq q_{a} \\
& =579 \leq 942 \ldots . . . \text { Syarat terpenuhi }
\end{aligned}
$$

\section{Penulangan Pondasi Telapak}

Luasan tulangan, As $=1.419 \mathrm{~mm}^{2}$, Jadi dipakai tulangan $=\mathrm{D} 19-200 \mathrm{~mm}$

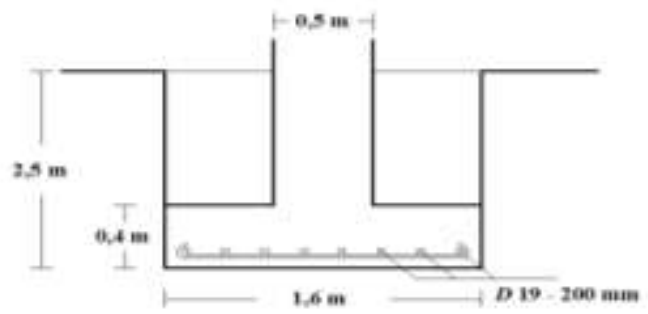

Gambar 11. Penulangan Plat Pondasi

\section{KESIMPULAN}

a. Dimensi Struktur Atas

1) Balok :

2. Lantai 1, 2 dan 3 diperoleh Dimensi $400 \times 550 \mathrm{~mm}$

3. Lantai atap/Ring Balk, diperoleh Dimensi 350 x $500 \mathrm{~mm}$

2) Kolom:

4. Lantai 1, 2 diperoleh Dimensi 500 x $500 \mathrm{~mm}$

5. Lantai 3 diperoleh Dimensi $450 \mathrm{x}$ $450 \mathrm{~mm}$

3) Tebal Plat Lantai sebesar $160 \mathrm{~mm}$.

b. Perbandingan perhitungan struktur

1) Gaya gempa yang bekerja pada struktur bangunan SRPMK lebih kecil dibandingkan dengan bangunan SRPMM sebesar 1,6\%.

c. Dimensi Struktur Bawah

1) Dimensi Pondasi Telapak

Lebar Pondasi arah $\mathrm{x}(\mathrm{B})=1,6 \mathrm{~m}$

Lebar Pondasi arah y $(\mathrm{L})=1,6 \mathrm{~m}$

Kedalaman Pondasi $=2,5 \mathrm{~m}$

2) Tulangan Pondasi diperoleh D19 dengan jarak $200 \mathrm{~mm}$

\section{DAFTAR PUSTAKA}

Anonimous (1987). Pedoman Perencanaan Pembebanan Untuk Rumah Dan Gedung. SKBI-1.3.53. 1987 Departemen Pekerjaan Umum. Jakarta.

Anonimous (2002). Standar Perencanaan Ketahanan Gempa Untuk Bangunan Gedung. SNI 03-1726-2002. Bandung.

Anonimous (2002. Tata Cara Perhitungan Beton Untuk Bangunan Gedung. SNI 032847-2002. Bandung.

G. Djatmiko S, dan S. J. Edy P. (1997). Mekanika Tanah 2. Kanisius, Yogyakarta.

Imran Iswandi, dan Hendrik Fajar (2010). "Perencanaan Struktur Gedung Beton Bertulang Tahan Gempa". ITB, Bandung. Pristianto, H., Amri, I., \& Rusdi, A. (2014, May 9). Pedoman Penulisan Tugas Akhir Fakultas Teknik Universitas Muhammadiyah Sorong 2014. http://doi.org/10.17605/OSF.IO/4VTJM.

W.C. Vis dan Gideon Kusuma (1993). "Dasardasar Perencanaan Beton Bertulang". Erlangga, Jakarta.

W.C. Vis dan Gideon Kusuma (1993). "Grafik dan Tabel Perhitungan Beton Betulang”. Erlangga, Jakarta. 